\title{
Explaining Digital Divide as a Consequence of Uneven Digital Opportunities between Urban and Rural Areas: A Case of Internet Usage among Senior High School Students in Kelantan, Malaysia
}

\author{
Tengku Mohamed Faziharudean and Hitoshi Mitomo
}

\begin{abstract}
This paper is based on a questionnaire survey that was conducted on senior high school students (both in urban and rural areas) in the State of Kelantan, Malaysia. Our objective is to present the causal relationship using Covariance Structural Analysis of the factors that are perceived to encourage the teenagers to use the Internet service. Based on the data collected from the survey, we can also make a comparison on the levels and patterns of the Internet usage between the urban and rural teenagers in Kelantan. Then, we come up with recommendations on how to address the issue of the diffusion of Internet usage, especially on how to bridge the digital gap between the urban and rural population.
\end{abstract}

Keywords: Covariance Structural Analysis, digital divide, survey, urban-rural issues JEL Classification: C88, R0

Abbreviations: ICT-Information and Communication Technologies, MECM-Malaysian Ministry of Energy, Communications and Multimedia, NIT-National Information Technology, PC-Personal computer, RMSEA- Root Mean Square of Approximation, SEM-Structural Equation Modeling, USA-United States of America

\section{Introduction}

The issue of digital divide based on where people live has become a much concern issue to every developing country in the world, as it will create further uneven digital opportunities between urban and rural populations. As for Malaysia, such geographical digital divide will upset the government "Vision 2020 NIT Agenda," which by the year 2020 all Malaysians will get access to the ICT and its applications.

Younger generations are perceived to be the largest segment in the population to use the Internet (90.0\% of Internet users in Malaysia are teenagers). Therefore, the Malaysian Government program for the ICT diffusion has also targeted schoolchildren. However, with more than 40. $0 \%$ of the Malaysian population is still living in the rural area ([16]), ICT diffusion that is always associated with high income level and urban life-style is a major challenge to be spread out to the public.

This study is an initial attempt to find out the variables that influence teenagers to use the ICT. By knowing those variables, we could make comparison of the usage pattern and see if digital divides do prevail based on the geographical location, specifically between the urban and rural population. Using a SEM we would find out the causal-effect relationship for the usage of the

Graduate School of Global Information \& Telecommunication Studies, Waseda University, 29-7 Building, 1-3-10 Nishi Waseda, Shinjuku-ku, Tokyo, 169-0051, Japan 
Internet by the senior high school students in Kelantan.

\section{Literature Review}

According to the MECM, the Internet penetration rate in Malaysia in the year 2000 is 39.5 per 1000 population. The fixed line penetration rate (an indicator for the tendency of the usage of the Internet service) for the urban areas being $32.7 \%$ as compared to the rural areas' $9.5 \%$ ([7]), shows the existence of digital gap between the urban and rural population in Malaysia. In contrast, previous study on digital divide conducted in developed nations such as the USA shows that the digital gap based on geographical area is almost insignificant. The national and rural average in the USA of the population using the Internet in the year 2001 were $54.0 \%$ and $53.0 \%$ respectively, that indicate a very little gap ([11]). However, the scenarios for the ICT diffusion in a developing nation are different from those of developed nations because the rural area is associated with lower standard of living. For younger generation living in rural areas, there are inadequate Internet facilities available in school or public places, and supporting infrastructures are not available.

There is also an argument that the ICT diffusion follows the "S" curve. The early adopters would be the elite urban population with higher income, and diffusion would occur subsequently to the larger segment of the population (including the rural population), when the technology itself became more familiar and common for the mass population. (see Benjamin M. Compaine, [2]). Therefore, there is no need to act precipitously on the issue of digital divide, and to let the market settle the issue. It is further explained by the spatial adoption potential theory that technological developments follow the filtering down process from the urban hierarchy (core area) to the peripheral area (see Roberta Capella, [14]). Being latecomers for ICT development also is not a disadvantage at all, as it might create a "window of opportunity" for the latecomers to "leap-frog" into new technological phase. The Internet can be spread efficiently with less government intervention directly in the diffusion process (see A. Sidorenko \& C. Finlay [1]), and it could bring higher economic growth to the nation when the technology became sufficiently affordable to replace previous dominant techniques.

Previous literatures and researches on digital divide suggested that the rate of adoption for the ICT would be much faster than the previous technologies. However, without any reliable research to support the assumption that ICT adoption can take place in a short period of time (especially in the developing nations), a proactive approach to accelerate the diffusion process of ICT must be initiated by the government to encourage the ICT usage by the public. In order for Malaysia to achieve its goal that all Malaysians will be ICT literate by the year 2020, the diffusion process must be accelerated to go beyond the natural process. The early adopter phase must be very short, and the diffusion process itself must take place without the exclusion of the large rural population.

\section{Study Methodology}

\subsection{Study Location}

We conducted the study in the State of Kelantan, located at the northeast of Peninsular Malaysia. (The location map of Malaysia and Kelantan are as shown in Figure I). Kelantan has the lowest penetration of the Internet usage in Malaysia, (with penetration rate of 12.5 persons per 1,000 populations) ([7]). In Kelantan, Kota Bharu and Tanah Merah demographically represent the overall (average) urban or rural environment in Malaysia respectively, with regards to the population, infrastructure or education facilities that are available in those locations. (Category for urban and rural areas are defined based on the guideline used by the Malaysian government departments and agencies when applying for the Federal Government loans and grants for development projects. Based on the guideline, only Kota Bharu is defined as the urban center in Kelantan.)

Kota Bharu is the capital city and the largest not only in Kelantan but also in the East Coast of Peninsular Malaysia, with a population of 406,662 (year 2000)[6]. On the other hand, Tanah 


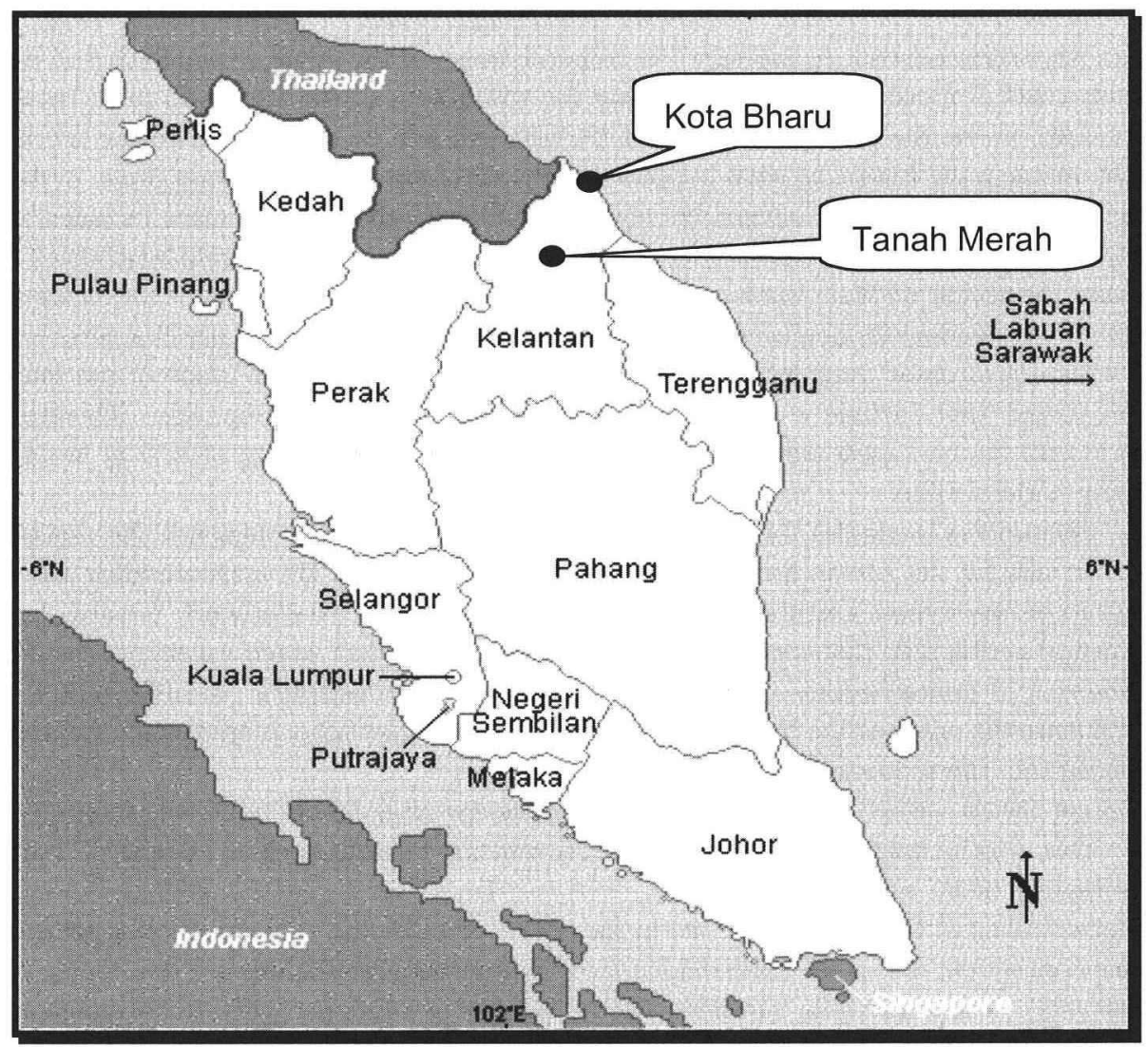

FIGURE I : Location Map of Kelantan, Malaysia

(Source: Flags of the World, flagsspot.net/flags/my (w.htm \# map))

Merah is one of the district administrative and a business center in Kelantan, with a population of 30,000 (year 2000) [6].

\subsection{Sample}

The respondents for this study are the senior high school students (17 years old). The reason for streaming the sample to senior high school students to represent the teenagers is because they are perceived most likely to be Internet literate than other teenagers in the high schools. As many of them (especially in the rural area) will enter the workforce in the coming year, the sample would be more representative of the public usage of the ICT. The sample size for this study was 300 . It consists of two high schools in Kota Bharu (200 samples) and two high schools in Tanah Merah (100 samples) representing the urban and rural samples respectively.

\subsection{Measurement Indicator and Variables}

It is argued that the Internet is not considered as a useful tool to measure the full potential usage of ICT by teenagers. Findings from previous surveys show that the popular service used in the Internet were chatting, e-mail or games (not limited to teenagers but also adults) that are merely entertainment and could not contribute significantly to improve the academic performance of the teenagers. If more "daily services" of information (including e-library) are available online, the shift of the current purpose of usage, from just entertainment, to dissemination of knowledge or 
commercial purpose is inevitable. Therefore, the teenager usage of the Internet or being networked is an important element to measure the responsiveness of the younger population to the ICT. This study itself is more interested in knowing the willingness of the teenagers to be networked. As mentioned above, the purpose of usage of the network will be expanded as more services are available online in the future, as what happened in the early days of the Internet usage in the USA, that was also merely for entertainment, but now has change to other activities that included banking or financial services as well. After all, the Internet literacy is the most accurate benchmark to date to measure the ability of Malaysians to get connected to the ICT network, as other indicators are vague or still misleading for empirical analysis. For example, the ability to use computer is mostly related to wordprocessor usage or playing computer games. Instead, the usage of the Internet is wider in scopes that include e-mail, chatting, acquiring the information, etc. Therefore, the Internet is still the best measurement to use as an indicator for the usage of ICT in Malaysia or developing nations alike.

The independent variables for this study are the factors that will influence the usage of the Internet service by the senior high school students in Kelantan. By understanding the causal relationship between those factors and the usage of the Internet, we can work towards having a governmental action plan that specifically targets those causes that would accelerate the diffusion of the Internet to the teenagers. The perceivable factors or independent variables that we think might influence the usage of the Internet service by the senior high schools students in Kelantan can be classified into the following four categories : -

1) Parent factor - whether the respondents' parents encourage them to use the Internet service or not. This also includes the background of respondents' families such as income, ICT literacy, and availability of PC at home.

2) Accessibility to the Internet service in the area - whether the respondents can get access to telephone connection, that is the main indicator of the Internet accessibility in a developing country. like Malaysia. The observable variables are the number of hours per week the respondents used the Internet either at home, schools, cyber cafes, community centers, etc.

3) Tutorial available to study ICT - whether Internet classes or courses to learn the ICT is available for the respondents either in schools, private institutions, community centers, etc.

4) Availability of alternative services that will rival the usage of the Internet service - that include watching television, listening to music from radio/CD or stereo, playing sports, spending time in library, etc., that is suppose to have a negative effect to the usage of the Internet service.

The survey has some limitations as follows:

1) Samples used were students, and their usage of the Internet service is limited.

2) For some questions, the respondents answer the questionnaire on behalf of their parent or the school authority. Therefore, we can only get a third party opinion on those questions asked.

\subsection{Scenario of the Internet Usage by the High School Students in Malaysia}

Although ICT is not formally taught as a subject in the public schools in Malaysia, for those schools that have computers, the subject is taught informally. Malaysian government has targeted that every school in Malaysia is to be equipped with a computer lab by the year 2002. The high school students in Malaysia are currently using the Internet as an additional source for them to obtain information for their school assignments, besides of having to gather information from reading text books or going to the library. Our samples in this study consist of schools that have computers and also Internet facilities and all the 4 schools indicate that they have given school assignments that require the students to use the Internet to get the information needed to complete the task. The overall scenario for the usage of the Internet by the high school students in Malaysia is considered to be at an initial stage. There are still problems regarding the basic telecommunication infrastructures to enable schools in the rural areas to have access to the Internet service. This 
is a different scenario from Japan where the high schools are well equipped with computers and Internet access regardless of the geographical differences. The Japanese teenagers are also well exposed to ICT education, many are using the mobile phones and as most of the Internet contents are in Japanese language, it makes the Internet attractive to be used.

\section{Descriptive Finding from the Sample}

The data obtained from the questionnaires were analyzed using SPSS 10.0 for Windows. The descriptive findings from the samples are as follows:

\subsection{Demographics}

The respondents consist of 129 (43.0\%) male and 171 (57.0\%) female students. The ICT literacy among the respondents is as shown in Table I.

$87.7 \%$ of the respondents knew how to use the computer for 6 years or less, indicating many of the schoolchildren became computer literate in secondary schools or high schools. Even though the computer literacy is very high among the respondents, the Internet literacy is lower, as the Internet is still a new technology and would take more time to be diffused to the public. Urban respondents are far in the lead in term of Internet literacy as compared to the rural respondents with a difference of $28.0 \%$ points. When tested using Spearmans "rho" correlation, it indicates that there is a correlation of 0.30 between geographical locations and Internet literacy. This situation is in line with the early adopter theory that new technology firstly diffuses to the urban population. Descriptively it proved to us that there is a digital divide between urban and rural respondents in term of the ability to use the Internet.

In term of gender, $75.4 \%$ male respondents and $73.7 \%$ female respondents are Internet literate, indicating no gender based digital gap. This is contrary to the popular belief that religion (in this case Islam) became the main obstacle for female to get access to the Internet that was indicated in a previous study in certain

TABLEI: ICT Literacy among Respondents in Urban and Rural Area (in percentage)

\begin{tabular}{|c|c|r|c|}
\hline No. & Item & Urban & Rural \\
\hline 1 & Computer literacy & $91.0 \%$ & $71.0 \%$ \\
\hline 2 & Internet literacy & $83.0 \%$ & $55.0 \%$ \\
\hline
\end{tabular}
Africa countries.

\subsection{Parent factor}

More than $90.0 \%$ of the respondents' parent encouraged their children to use the Internet service irrespective of where they live (showing that there is a significant agreement on attitude of the respondents' parents based on Chi-square test for goodness of fit). This indicates that most of the public in Kelantan realized the importance of ICT knowledge for their children to acquire.

In this study, we use the literacy of the respondents' father as an indicator to show the parent influence for the respondents to use the Internet. Almost all of the fathers are in the workforce, and $47.3 \%$ of the respondents' fathers are ICT literate. Table II shows the respondents' father's ICT literacy in the urban and rural area. There is a significant difference based on ICT literacy of the respondents' father (Chi-Square test for goodness of Fit) based on the geographical area where they live. However, the gap narrows down with regard to the respondents who are Internet literate, especially more rural respondents who are Internet literate have fathers who are also ICT literate. The fact that $71.3 \%$ of the respondents' parent income is more than RM 600.00 per month indicates that the respondents are mainly from the average and above average family background in Kelantan (as shown in the Pie Chart in Figure II).

$35.1 \%$ of the respondents who are Internet literate are from family with income of more than RM 1,500.00 per month, although they represent only 29.3\% (shown in Figure II) of the total number 
TABLE II. Respondents Father's Literacy, Parent's Income and Ownership of P.C. at Home

\begin{tabular}{|c|l|c|c|}
\hline No. & \multicolumn{1}{|c|}{ Item } & Urban & Rural \\
\hline \multirow{2}{*}{1} & Father's ICT Literacy-Overall Sample & $52.0 \%$ & $38.0 \%$ \\
& Father's ICT Literacy-among Respondents Who are Internet Literate & $56.0 \%$ & $45.5 \%$ \\
\hline \multirow{2}{*}{2} & Parent's Income above RM 600.00 per month-Overall Sample & $77.0 \%$ & $60.0 \%$ \\
& Parent's Income>RM600.00 per mo - among Internet Literate Respondents & $81.3 \%$ & $76.4 \%$ \\
\hline \multirow{2}{*}{3} & Own Personal Computer at Home-Overall Sample & $64.5 \%$ & $46.0 \%$ \\
& Own P.C. at Home-among Respondents Who are Internet Literate & $73.8 \%$ & $67.3 \%$ \\
\hline
\end{tabular}

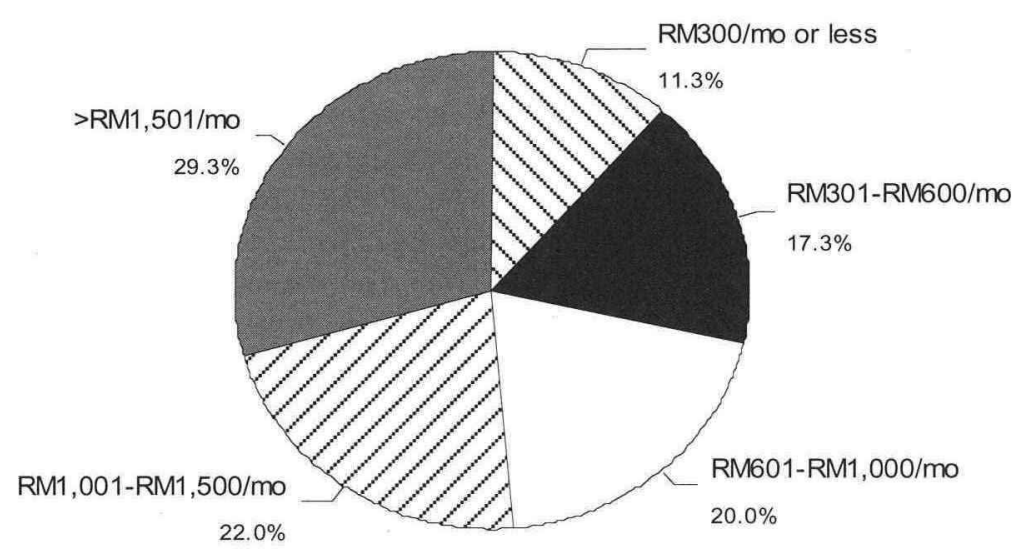

FIGURE II : Pie Chart of the Distribution of the Respondents Parent's Income

of respondents. Only $20.0 \%$ of the respondents who are Internet literate come from parent with income of below RM 600.00 per month (shown in Figure II), indicating wealth played an important determinant factor for the high school students to be Internet literate.

In term of urban-rural comparison, Table II shows that there is a significant difference in term of respondents' parent income between urban $(77.0 \%)$ and rural $(60.0 \%)$ respondents (Pearson Chisquare test) for income above RM 600.00 per month. Among the respondents who are Internet literate, the gap in term of parent income also narrows down as the majority of the respondents who are Internet literate come from average to above average family background. Digital divide between the urban and rural respondents did prevail based on their parent income.

PC ownership seems to relate positively with the parent income. Table II shows that there is a different in term of urban-rural respondents who own PC at home. However, the gap is closing up among the respondents who are Internet literate, indicating to us again that the respondents who are Internet literate are also most likely to own a PC.

\subsection{Accessibility of the Internet service at the area}

Both Kota Bharu and Tanah Merah have good accessibility to the telecommunication services. Table III give the number of telephone connections (for residences purposes) and cyber cafes in both locations.

From our survey we found out that the most popular locations where the respondents are using the Internet service are at home, followed by cyber cafes and schools (as shown in Figure III) for both the urban and rural respondents who are Internet literate.

The pattern for usage of the Internet service between the rural and the urban respondents shows some differences. Although the urban and rural respondents use more of the Internet service at 
TABLE III. Telephone Connections and Cyber Cafe in Survey Location

\begin{tabular}{|c|c|c|c|}
\hline No. & Item & Location & Quantity \\
\hline \multirow{2}{*}{1} & Telephone connections (residences) & Kota Bharu & 27,140 \\
\cline { 3 - 4 } & & Tanah Merah & More than 4,000 \\
\hline \multirow{2}{*}{2} & Cyber cafe & Kota Bharu & 57 \\
\cline { 3 - 4 } & & Tanah Merah & 3 \\
\hline
\end{tabular}

Source: Kota Bharu Municipal Council and Tanah Merah District Council

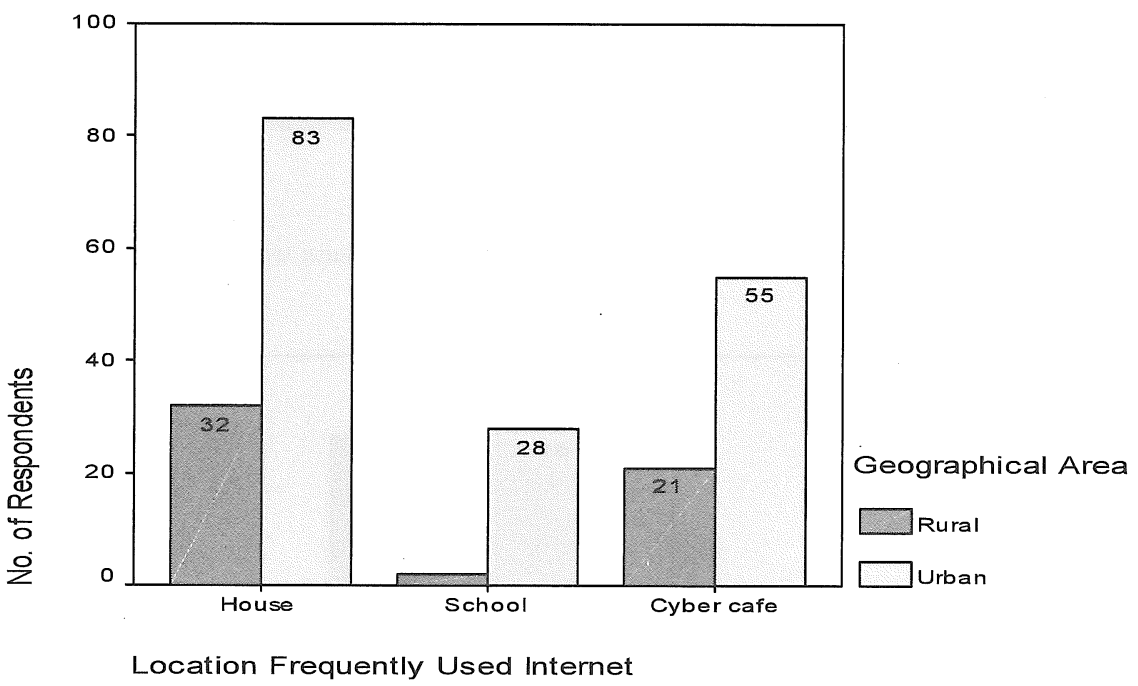

FIGURE III : Bar Chart of the Locations Where the Respondents Frequently Used the Internet

home, a larger percentage of the rural respondents (38.2\% as compared to the urban respondents of $33.1 \%$ ) are using the service at cyber cafes, and almost all of them do not use Internet at schools (3.6\% for the rural respondents as compared to $16.9 \%$ for the urban respondents).

From Figure IV, we can also consider the number of hours per week the respondents using the Internet to be low, with the majority of the respondents both in the rural and urban area were using the Internet service less than 7.0 hours per week.

\subsection{Tutorial available for the respondents to study ICT}

More than half of the respondents ( 177 respondents) do not have formal education on how to use the Internet, and $82.1 \%$ of those who have attended ICT classes or courses (among those who are Internet literate) are urban respondents. Figure $\mathrm{V}$ shows the percentage of the urban and rural respondents (who are Internet literate) that have attended ICT classes before. $60.0 \%$ of the rural respondents never had a chance to attend ICT classes as compared to $61.0 \%$ of the urban respondents who have attended ICT classes.

Among those urban respondents, $88.7 \%$ attended formal education for ICT in schools. However, many of the rural respondents attended the ICT classes/courses from community centers or private tutorials, showing that schools played a lesser role for the diffusion of ICT education for the rural teenagers. We can conclude from here that the rural respondents still lack behind in formal education in ICT. 


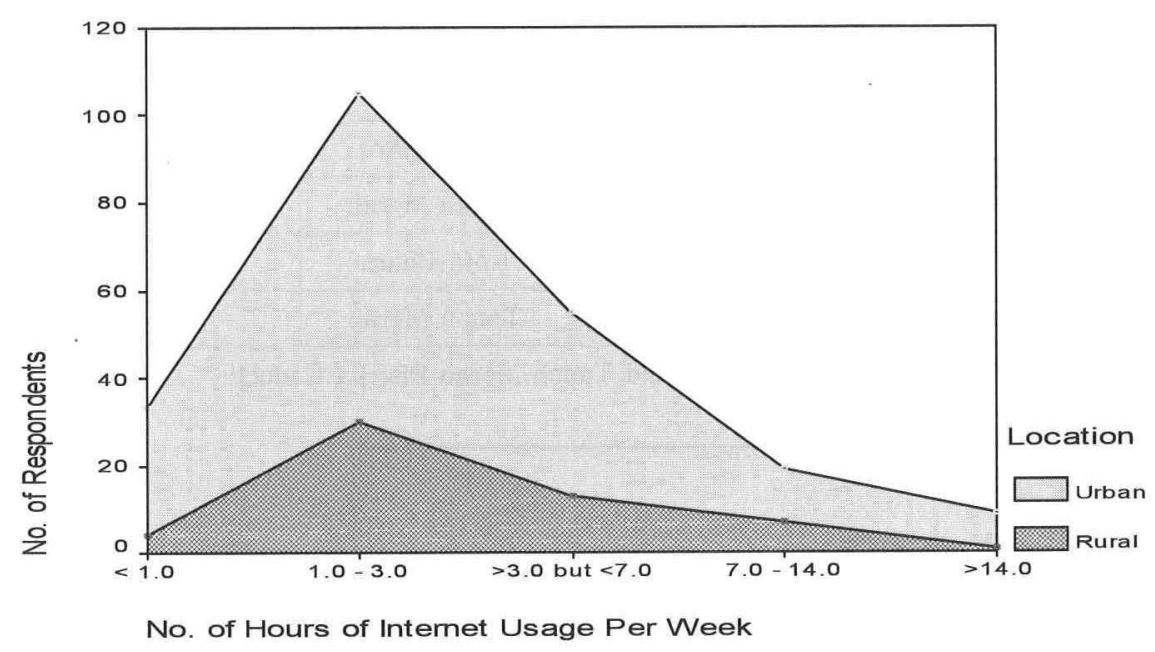

FIGURE IV : Graph of the No. of Hours per Week the Respondents were using the Internet

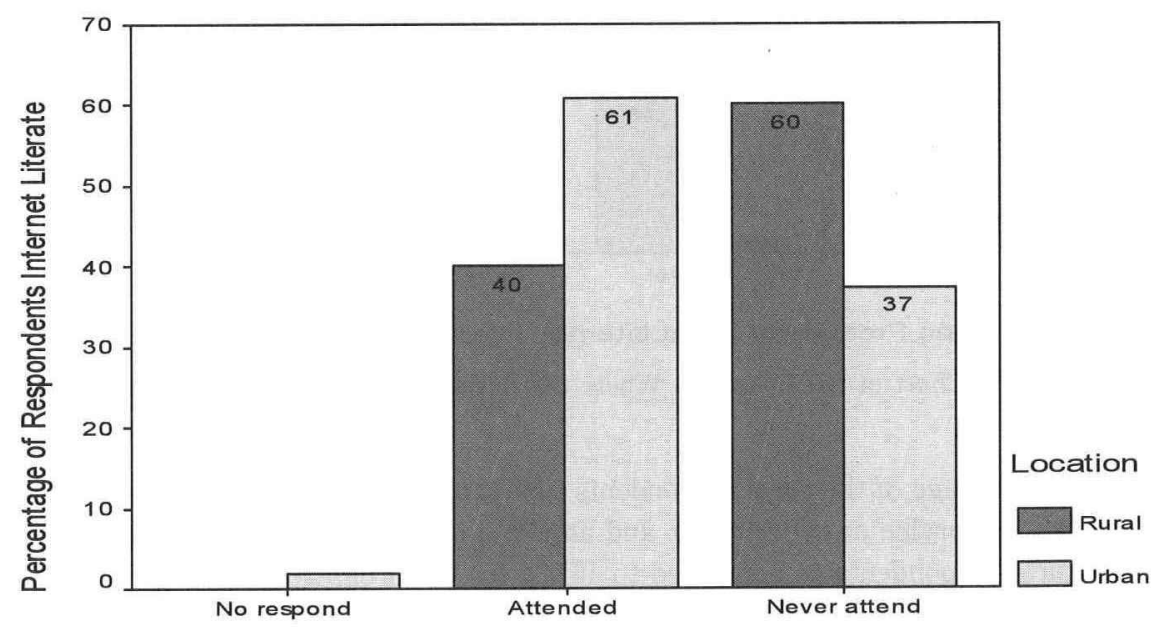

IT Class Attended

FIGURE V : Bar Chart of the Percentage of the Respondents who have Attended IT Classes

\subsection{Alternative services that rival the usage of the Internet}

Among the activities such as watching television, listening to music, spending time in the library or playing sports, the most popular is watching television as shown by the ranking that is based on the median of the frequency of the usage of those services by the respondents (as shown in Table IV). Surprisingly, the school library is not a popular place for the respondents to spend time with. There are also no differences either for the urban or rural respondents with regard to the number of hours they spent on those activities.

\section{SEM Modeling and Analysis from the Study}

Figure VI below shows the SEM that we have established from this survey, to find the causal relationship between some variables and the usage of the Internet by the senior high school students in Kelantan. Our final model consists of 4 latent variables (in oval shape boxes similar to the 
TABLE IV. Respondents Ranking of the Most Frequently Used Alternative Services

\begin{tabular}{|c|c|c|}
\hline Rank & Type of Services & No. of hours per week \\
\hline 1 & Watching Television & 7.0 hour \\
\hline 2 & Listening to music & 6.5 hour \\
\hline 3 & Involved in sport activities & 3.0 hour \\
\hline 4 & Spending times in the library & 1.5 hour \\
\hline
\end{tabular}

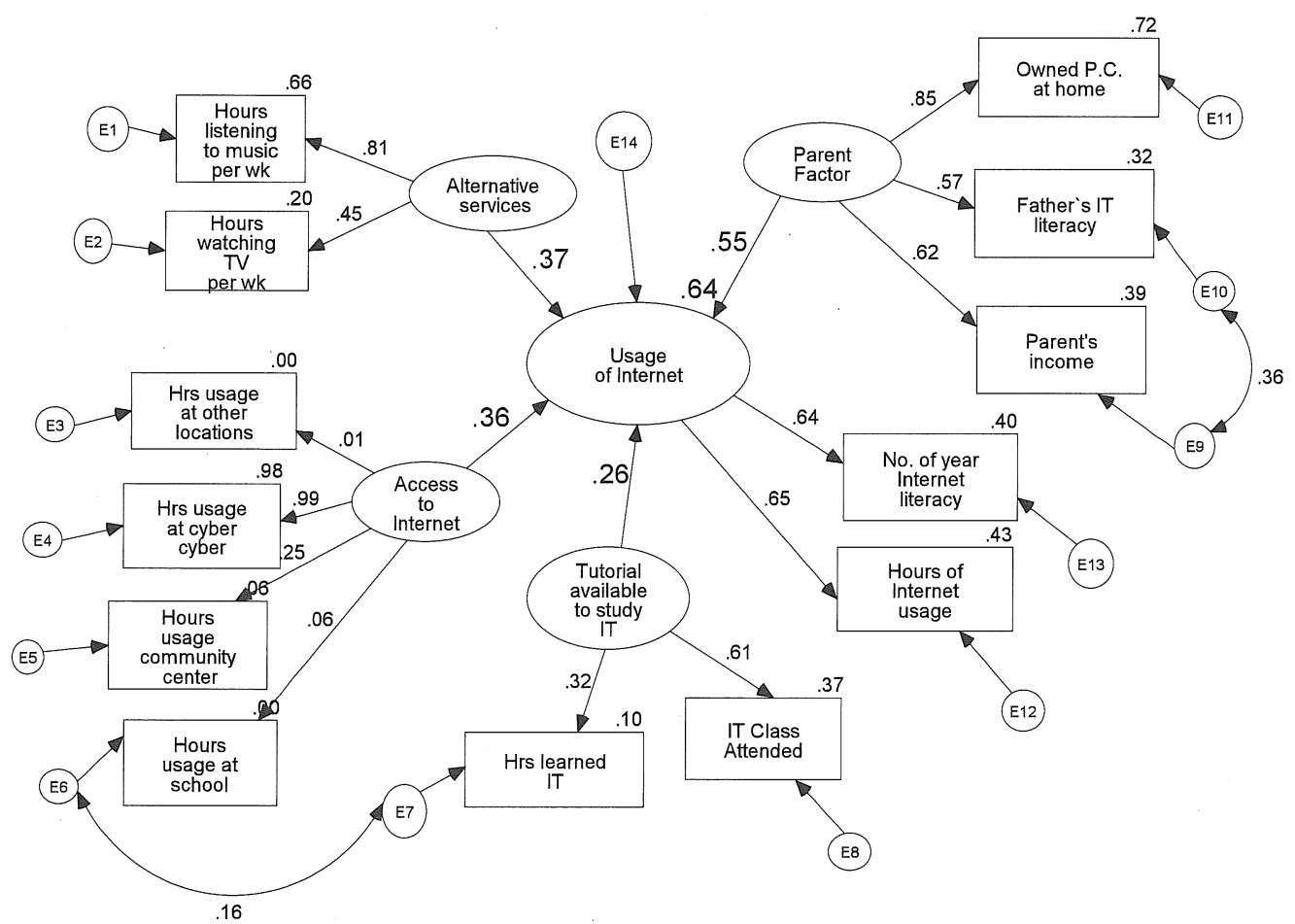

FIGURE VI: SEM for Factors that Encourage the Respondents Usage of the Internet

dependent variable), and each latent variable have at least 2 observable variables (in rectangular boxes) that we obtained from our questionnaire survey, and assumed to reflect the underlying latent variables. E1 to E14 are the residuals or unique factors, as any variable predicted by another variable must have a residual value. E1 through E11 are the unobservable variables unique to the latent variables it is affecting, whereas E12 through E13 are the unique unobserved variables affecting the manifest variables to the dependant variable. E14 represents the unique variable affecting the dependant variable.

\subsection{Parent factor}

"Parent factor" is the most influential independent variable that can encourage the senior high school students in Kelantan to use the Internet (standardized regression coefficient of 0.55). From the model, the observable variables used to measure parent factor are "parent income", "respondents' fathers Internet literacy" and "ownership of PC". Among the observable variables, the "ownership of PC" (standardized regression weight of 0.72 ) is the most contributing. It is not a 
surprise as more than $40.0 \%$ of the respondents who are Internet literate in our survey intially learn how to use the Internet at home as oppose to school or other places. Home also is the most popular location among the respondents to use the Internet.

The residual or the error variances for "respondents' father ICT literacy" and "parent income" have a strong positive correlation of 0.36 .

\subsection{Alternative services that rival the usage of the Internet}

The observable variables used for this model (based on the most popular activities that respondents like to do) are the number of hours per week the respondents spent watching television and listening to music. The alternative services that rival the Internet, surprisingly have a significant positive effect to the usage of the Internet (standardized regression coefficient of 0.37 ), not a negative coefficient as expected. The positive correlation found from this analysis can be explained by two factors :

1) In the case of Malaysia, where the latest information or trend could not spread fast enough through the traditional media like newspaper or television, the Internet would be the main source for the adventurous younger generation to search their favorite music, information, etc. Therefore, the alternative services actually complement the Internet service, and not becoming a rival service as initially thought.

2) The number of hours the senior high school students usage of the Internet is basically less than two hours per day. The Internet facilities in public places or schools are limited, and the usage at cyber cafes is still costly for long hour usage. Furthermore, to be online at home also required parent approval, cost consideration, etc. Therefore, "alternative services that rival the Internet" still did not play a significant role to rival the usage of the Internet service by the students.

\subsection{Accessibility to the Internet service in the area}

Access to the Internet service is available either in the respondents' houses, schools, cyber cafes or community centers, or other places such as in houses of friends/relatives. For the purpose of our modeling, we didn't use the access available at home as our observable variable in order to avoid possible multi-colinearity. Accessibility to the Internet service also has a significant effect for the usage of the Internet by the respondents (standardized regression coefficient of 0.36 ), meaning that the respondents will be encouraged to use the Internet service if access to the service is within their "reach". The usage of the Internet at cyber cafes (besides at home) is the most influential factor (standardized regression weight of 0.99 ) as compared to at schools (standardized regression weight of 0.06 ), showing the major role played by the cyber cafe in Internet diffusion for the teenagers. The role of school for the diffusion of Internet usages diminishes as there are limited number of computers with Internet access available in school, and the lack of privacy when sending e-mail or chatting (the two most popular usages of the Internet among the teenagers).

\subsection{Tutorial Available to Study ICT}

The observable variables to measure if the respondents have access to tutorial or formal education in ICT are the time spent by the respondents to learn ICT in classes/courses, and the basic question whether the respondents ever have a formal education on ICT or not. This factor does not have a significant effect to the usage of the Internet like the other three potential variables (standardized regression weight of 0.26 ), as almost half of the respondents did not have formal education in ICT. However, as the majority of the respondents think that ICT classes or courses should be taught in school, we perceived that the respondents will be motivated to use the Internet service if there are tutorial available for them.

The residual variances for "hours learned ICT" and "hours usage at schools" (from the factor "accessibility to the Internet") has a positive correlation of 0.16 , as many of the respondents received 
formal ICT education in schools.

\subsection{Fitness of the SEM}

The square multiple correlation for the model is 0.64 . Therefore, the four independent variables together explained $64.0 \%$ of the variance of the dependent variable (that is the usage of the Internet service by the senior high school students in Kelantan). When we check the model by the Chi-Squared test, the Chi-Squared value is 94.938 with a probability level of 0.002 . Therefore, at $95.0 \%$ confidence interval, we can reject the null hypothesis, and can conclude that the model is statistically significant. Further testing indicates that as the Tucker-Lewis index is 0.979, the model is considered to have a good fit; and that the RMSEA is 0.053 , the model is considered to be fairly fitted on RMSEA measurement.

\section{Recommendations and Conclusion}

From our descriptive analysis, we found out that there is a digital divide based on the usage of Internet among the urban and rural senior high school students in Kelantan. However, the respondents shared the same causal relationship, as "parent factor" is found to be the most influencing factor for the Internet diffusion among teenager. Parent active participation in the ICT, regardless in urban or rural area will have a direct and indirect effect for the students to use the Internet as proven from this study, as the Internet literacy among the respondents highly correlates with having $\mathrm{PC}$ at home. Therefore, Malaysian government should tailor its ICT programs targeting the active participation of parents instead of just concentrating on the students.

Further improvement is needed to better equip schools throughout the country with more computers with the Internet access and also technical support. Schools have played a major role to initially educate the students to be computer literate (as proven from this survey); therefore, it should continue to play an active role to ensure that students are also Internet literate when they left high schools. The policy of improvement in ICT availability in schools will benefit the lower income group of the population who normally live in rural area and most probably did not own PCs at home. School's role in getting diversified students background to use the Internet must be strengthen, especially in the rural areas, to bridge the digital gap among the urban and rural students, more importantly among the rural students from lower income background.

The important role of cyber cafe for the diffusion of the Internet among the teenagers in Malaysia cannot be denied, especially when it come to bridging the digital gap between the rural and urban teenager. The local government initiatives are needed to encourage the opening of more cyber cafes, and it is also important to have cooperation with the major telecommunication company and owners of cyber cafes to ensure the charging rate to be networked is affordable for the students. Our study proved that when the authority could not provide the Internet service at an affordable price to the population (in this case the teenagers) or effectively (measured by the convenience for the users, such as the issue of privacy), cyber cafes played a significant and effective role to diffuse the technology to the rural teenagers. Therefore, cyber cafe roles in the diffusion of the Internet usage among the teenagers must be fully optimized.

\section{References}

[1] Alexander Sidorenko and Christopher Findlay, 2001, The Digital Divide in East Asia, Asia Pacific Economic Literature, Volume 15, Number 2, November 2001.

[2] Benjamin M. Compaine (edited), 2000, The Digital Divide: Facing a Crisis or Creating a Myth?, MIT Press Spurcebooks, USA.

[3] E. Hargittai, 2002, Second Level Digital Divide: Differences in People's Online Skills, First Monday, Volume 7, Number 4, April 2002. http://firstmonday.org/issues7_4/ hargittai/index. html. 
[4] H. Russel Bernard, 2000, Social Research Methods: Qualitative and Quantitative Approaches, Sage Publications, Inc. California, USA.

[5] James L. Arbuckle and Werner Wothke, 1999. Amos 4.0: User's Guide, SmallWaters Corporation, USA.

[6] Kelantan State Economic Planning Unit (KSEPU), 2002, State of Kelantan Socioeconomic Profile 2001.

[7] Malaysia Ministry of Energy, Communications and Multimedia, 2000, Report on I.T. Development.

[8] Maryann P. Feldman and Albert N. Link (Edited), 2001, Innovation Policy in the Knowledge-based Economy, Kluwer Academic Publisher Group.

[9] Marius Brulhart, 1998, Economic Geography, Industry Location and Trade: The Evidence. The World Economy, Volume 21.

[10] Masahisa, Fujita, Paul Krugman and Anthony J. Venables, 1999, The Spatial Economy : Cities, Regions and International Trades, The MIT Press, Cambridge, Massachusetts, London, England.

[11] National Telecommunications and Information Administration (NTIA), 2002, A Nation Online : How Americans Are Expanding Their Use of the Internet, at http://www.ntia.doc.gov/ntiahome $/ \mathrm{dn} / \mathrm{html} /$ anationonline2.htm.

[12] Organization for Economic Co-operation and Development (O.E.C.D.) Report, 2000, Learning to Bridge the Digital Divide, OECD Publications, France.

[13] Peter Nijkamp (Edited), 1994, New Borders and Old Barriers in Spatial Development, Avebury Ashgate Publishing Limited.

[14] Roberta Capello, 1994, Spatial Economic Analysis of Telecommunications Networks Externalities, Avebury Ashbury Publishing Ltd, Vermont, U.S.A.

[15] Sheridan J. Coakes \& Lindall G. Steed, 2001, SPSS : Analysis Without Anguish, John Wileys \& Sons Australia Ltd. Singapore.

[16] The Global Information Report 2001-2002: Readiness for the Networked World (GITR), 2002, Center for International Development at Harvard University, Massachussets, U.S.A., Oxford University Press.

[17] Thomas R. Black, 1999, Doing Quantitative Research in Social Sciences : An Integrated Approach to Research Design, Measurement and Statistics, Sage Publication Ltd., Great Britain.

[18] Tengku Mohamed Faziharudean and Hitoshi Mitomo, 2002, Bringing Internet to the Mass Public in Malaysia: A Study on the Factors that Influence the Usage of the Internet by Senior High School Students in State of Kelantan, Malaysia, paper presented at Pacific Regional Science Summer Conference, 2002, June 2002, Bali.

[19] Tengku Mohamed Faziharudean and Hitoshi Mitomo, 2002, Digital Divide as a Consequence of Uneven Digital Divide between Urban and Rural Areas: A Case of Internet Usage Among Teenagers in Malaysia, paper presented at Japan Regional Science Association International Annual Meeting, 2002, October, Sapporo.

[20] Uma Sekaran, 1992, Research Methods for Business, (2 ${ }^{\text {nd }}$ Edition), John Wiley \& Sons, Inc. 